\title{
'Want' is a lexical and conceptual universal
}

\section{Reply to Khanina}

\author{
Cliff Goddard and Anna Wierzbicka \\ University of New England, Australia / Australian National University
}

\begin{abstract}
The question of whether or not all languages have a word for 'want' (as in 'I know what you want, I want the same') is far more important than many linguists appear to realize. Having studied and debated this question for many years, we welcome Olesya Khanina's (2008) paper "How universal is 'wanting'?", which, we believe, addresses a question of fundamental importance. Our own view - which we have sought to substantiate in a large number of publications, over many years (cf. Wierzbicka 1972, 1996; Goddard 1991, 2001; Goddard and Wierzbicka eds. 1994, 2002; Peeters ed. 2006) - is that WANT is a universal semantic prime, i.e. an indivisible unit of meaning with a lexical exponent in all languages. In the present article, we argue that although Khanina has produced valuable results about cross-linguistic patterns in the polysemy of exponents of WANT, she has failed to demonstrate her concluding point, namely, "that 'want' is not a universal semantic prime in the sense of the Natural Semantic Metalanguage ... [and] that the inclusion of WANT in this list [of semantic primes] is indeed false" (p. 848). Briefly, we will argue that Khanina's conclusion depends, first, on an a priori decision not to recognise the existence of polysemy; and second, on a misunderstanding of the NSM position on what it means to be a lexical exponent of a semantic prime. We will also argue that 'wanting' constitutes an indispensable conceptual building block in human communication and cognition, and in linguistic and psychological theorizing about communication and cognition.
\end{abstract}

\section{Empirical aspects of Khanina (2008)}

Khanina's paper is a cross-linguistic survey, based chiefly on available grammars of 73 languages, of the range of use of translational equivalents of English 'want'. She introduces the venture by noting that "for a European, wanting seems to be a cultural prime, something self-evident and in no need of explanation" (p. 818). She asserts that its easy translatability from one European language to another is what underlies "the Eurocentric conception of WANT as a lexical or even semantic universal". In 
so saying, she ignores the empirical base of Goddard and Wierzbicka (eds. 1994), which tested the translatability of wANT across 17 languages, most of them nonEuropean, and the studies in Goddard and Wierzbicka (eds. 2002), which included a detailed treatment of language-internal arguments for polysemy of the exponent of WANT in a European language - Spanish. ${ }^{1}$ We will return to these studies later, but first it seems advisable to review the arc traversed by Khanina's (2008) study.

Reserving discussion of theory and methodology for the time being, Khanina proceeds immediately to describe her own methodology. The term "polysemy" is not yet mentioned. She extracts data on translational equivalents of 'want' from 73 languages on which good quality documentation was available, labelling the relevant morphemes or constructions as "desiderative", in order to avoid the presumption that 'wanting' is a universal. She then observes that in roughly two-thirds of the sample the desiderative items can also have additional translational equivalents, such as 'like', 'feel' and 'must'. No surprises here. NSM researchers themselves have often discussed examples of polysemy involving exponents of WANT.

The next step is to investigate the distribution of these different translational equivalents: Are they conditioned by morphosyntactic or semantic features, either fully or partially? Or is there no such conditioning, i.e. the interpretation is influenced only by discourse and pragmatic factors, so that both interpretations are always possible depending on the context? We would like to sound a note of reserve about the term "conditioning", but to continue, Khanina reports that full conditioning is found in many languages and partial conditioning in many others. Importantly, as we see it, she nominates not a single language in which there is positive evidence of "no conditioning", because it turns out that one cannot distinguish this possibility from a lack of high-quality information (p. 822). She does note, however, that many sources present the possibility of ambiguity without stating anything about possible distinguishing factors. In any case, it is uncontroversial that many languages lack any word that can only be used to mean 'want'.

Reviewing the data in her Sections 2-6, Khanina makes some valuable contributions to typological semantics. She observes (p. 824) that in addition to 'wanting', the apparent additional meanings expressed by desideratives fall into two clearly distinct and roughly equal-sized groups - "mental-emotive" and "modal" - and she proceeds to survey the most common meanings in each category. Among the modal group these are: near future/prospective, necessity, and "intention" (though how the latter is distinguished from 'want' is unclear). Several other less common meanings are also identified, though again how some of these distinctions are made is rather unclear, e.g. how is necessity distinguished from obligation, how is purpose distinguished from intention and wanting?

Among the mental-emotive group, the most common meaning is 'like/love' (on the understanding that 'like' and 'love' may or may not be distinguishable 
from one another in some languages), with less common alternate meanings being 'think' and 'say'. Interestingly, in this case it seems that grammatical differences nearly always correlate with the different meanings. One should say, actually, that such differences are nearly always reported, and this is not surprising, for the differences concern different complementation strategies. Macro-grammatical facts of this kind are of high interest to descriptive linguists. Other, still less common, alternate meanings were 'feel', 'accept', 'agree', 'hope' and 'know'. Again, how some of these "meanings" are to be distinguished from 'want' or from 'like' is unclear, and Khanina admits that it is sometimes hardly possible with the available information.

A significant correlation was observed between word-class and alternate meaning: "Desiderative verbs and desiderative nouns tend to have additional mental-emotive meanings, but not modal meanings; by contrast, desiderative affixes and desiderative particles tend to have additional modal meanings, but not mental-emotive ones" (p. 839). This makes sense in terms of what we know about the cross-linguistic expression of modal meanings.

This concludes the review of the empirical side of Khanina's study. We have omitted some points, but covered what seems to us to be essential. It is notable that throughout her presentation Khanina endeavours to remain neutral about matters of semantic interpretation: in particular, though she uses English as an informal metalanguage for describing "meanings", she reserves judgment about whether the existence of alternative or multiple translational equivalents does or does not imply the existence of emically real alternate meanings in individual languages. Put another way, she has remained neutral on the question of polysemy vs. generality.

\section{Khanina's (2008) critique of polysemy}

In her concluding Section 7, however, Khanina comes out against polysemy - not just in the case of particular languages, but in general. Even more surprisingly, perhaps, the reasoning involved is not conceptual but methodological. Essentially, according to her, it is too hard and too problematic to decide on questions of polysemy, so we are better off assuming that there is none. To replace the very idea of polysemy, i.e. distinct senses that can be established on language-internal evidence and argumentation, Khanina declares her preference for Gil's (2004) notion of "macrofunctionality" (essentially, semantic vagueness or generality).

This is the approach I propose to take here for desideratives. Some desideratives are macrofunctional, while others are not: the so-called 'multiple meanings' are thus reinterpreted as macrofunction (p. 843). 
As far as we can see, Khanina does not advance any principled argument for this radical "no polysemy" position. She simply adopts it by fiat. Of course, if lexical polysemy is ruled out in advance, then it is obvious that there can be no precise lexico-semantic universals in the world's languages. On the basis of the cross-linguistic investigations carried out by NSM researchers themselves, we could immediately declare not only that WANT is not a universal semantic prime, but that neither are SAY, BECAUSE, or BODY (to mention only a few) - because it has been well-established that exponents of these primes are often polysemous in different languages (Goddard 2001), with non-identical secondary meanings in addition to their shared semantically primitive meaning.

When we say that Khanina offers no "principled argument" against polysemy, we do not mean to say that she offers no arguments at all, but her arguments are based on examples - examples of cases where, according to her, it is impossible or invidious to decide on questions of polysemy. Her main example concerns the classic puzzle posed by the English word blue, as opposed to its two Russian counterparts sinij (roughly equivalent to English 'dark blue') and goluboj (roughly equivalent to English 'light blue'). ${ }^{2}$ Khanina asserts: "There is no way to tell whether the first language is splitting up one 'originally' unitary semantic unit, or whether the second language is unifying two 'originally' distinct units" (p843). In our view, however, it is incorrect to frame the question in this fashion. To do so assumes that one particular word is basic and unitary, overlooking the obvious possibility that all three words are complex in their semantic structure, constructed from smaller semantic units which are shared between both languages. This is in fact the position that has long been argued in NSM work (Wierzbicka 1990, 2005, 2008). No "colour" words in any language are semantically unitary. The meanings of all of them, including English blue, and Russian sinij and goluboj, can be resolved into combinations of semantic primes, such as PEOPLE, SEE, SAY, KNOW, LIKE, and semantic molecules, such as 'sky', 'sea', 'fire', and 'sun', which themselves can ultimately be defined in terms of semantic primes.

In our view, the viability of the traditional notion of polysemy is the key theoretical difference between our position and that of Khanina. Of course, it goes without saying that many linguists have expressed unease about the concept of polysemy, particularly on whether it is always possible to draw a sharp line between polysemy (multiple distinct senses) and generality (a single broad meaning). There are indeed methodological problems associated with the treatment of polysemy in much contemporary linguistics and lexicography (Wierzbicka 1996: Ch. 9; Goddard 2000). In our view, however, the methods of NSM semantics, developed over three decades of detailed semantic research, provide solutions to these problems. As we will show shortly, language-internal reductive paraphrase provides a principled "litmus test" for resolving questions of polysemy vs. generality. 
Before that, we would like to note that Khanina's logic incurs a conceptual problem for her own program which she occasionally acknowledges, but never faces squarely, i.e. what is the basis for cross-linguistic comparison if every individual language has its own unique macrofunctions? What is the status of her use of English labels as a way of discussing and comparing meanings? Here is what she says:

Following the same logic, the label 'desideratives' is worth using only as a starting point for investigation or a useful methodological heuristic, while it might not be a pertinent reality in the languages of the world. (p. 844)

But if what is seen as "desiderative" (or 'wanting') is not a semantic reality in the languages of the world, how could it possibly be a "useful heuristic"? Wouldn't it actually be a "false compass", pointing us towards ethnocentric and misguided conclusions?

\section{Establishing polysemy by language-internal reductive paraphrase}

As argued at length in previous works, language-internal reductive paraphrase furnishes a workable and decisive procedure for resolving questions of polysemy, in addition to various syntactic and distributional tests that are widely used in lexicography. We will illustrate this with the well-known situation of the verb querer in Spanish, as illustrated in these examples:

(1)
a. Quiero algo.
want:1sG.PRES something
'I want something.'
b. No quiero esto.
not want:1sG.PREs this
'I don't want this.'

(2) Te quiero.

you love:1SG.PRES

'I love you.'

Does it have two (or more) meanings, such as 'want' and 'love/like', as traditionally assumed, or does it represent a single Spanish-specific macrofunction that happens to range across two (or more) words in English? Travis (2002) presents an incisive discussion. Travis notes the existence of syntactic differences between the two meanings, such as the fact that only querer 'want' can take a propositional complement. Quiero comer fruta [want-1sG.PREs eat.INF fruit], for example, can only mean 'I want to eat fruit'. The conclusive argument, however, is the test of paraphrase. 
$[\mathrm{O}]$ ne can show conclusively on semantic grounds that querer is polysemous as (i) the two uses cannot be captured by one definition, and (ii) querer wANT is needed in the explication of querer 'love', as can be seen in the following tentative explication. [...] querer 'love/like' implies good feelings towards someone, caring for their well-being (wanting them to feel something good, not wanting bad things to happen to them), and wanting to look after them (wanting to do good things for them). As the explication suggests, it can be used very widely, including to describe such feelings between parents and children, between couples, and also between siblings, friends, workmates, etc. (Travis 2002: 192-193)

Travis's explications are given below, in parallel Spanish and English versions. ${ }^{3}$ This language-internal paraphrase exercise establishes that querer has two meanings, and that querer ${ }_{1}$ WANT is the simpler of the two. For a similar argument about the Yankunytjatjara word mukuringanyi, see Goddard (1991).

[A1] $X$ quiere $_{2}$ a $Y$ ('X loves $\left.\mathrm{Y}^{\prime}\right)$ :

$\mathrm{X}$ siente algo bueno cuando está con $\mathrm{Y}$

$\mathrm{X}$ siente algo bueno cuando piensa en $\mathrm{Y}$

$\mathrm{X}$ quiere ${ }_{1}$ que $\mathrm{Y}$ sienta algo bueno

$\mathrm{X}$ no quiere ${ }_{1}$ que nada malo le pase a $\mathrm{Y}$

$\mathrm{X}$ quiere ${ }_{1}$ hacer cosas buenas para $\mathrm{Y}$

[A2] $X$ quiere $_{2}$ a $Y$ ('X loves $\mathrm{Y}$ '):

$\mathrm{X}$ feels something good when $\mathrm{X}$ is with $\mathrm{Y}$

$\mathrm{X}$ feels something good when $\mathrm{X}$ thinks of $\mathrm{Y}$

$\mathrm{X}$ wants $\mathrm{Y}$ to feel something good

$\mathrm{X}$ doesn't want anything bad to happen to $\mathrm{Y}$

$\mathrm{X}$ wants to do good things for $\mathrm{Y}$

The proposal that querer has two distinct meanings also corresponds to the intuitions of native speakers of Spanish. Consider a sentence like Quiero a Juan, for example (the preposition $a$ normally marks a human NP object of querer). The meaning expressed by quiero in this context normally corresponds to that explicated in $[\mathrm{A} 1] /[\mathrm{A} 2]$, i.e. (roughly) 'I love Juan'. In appropriate contexts, however, the 'want' meaning is also possible; for example, No quiero a Pepe en mi equipo, pero quiero a Juan 'I don't want Pepe in my team, but I want Juan'. Spanish speakers are in no doubt that these are two distinct meanings. We note in this connection that Khanina is prepared to hypothesize that "macrofunctionality" has cognitive consequences. Even in cases where a word covers a wide spectrum of physical and mental states, she says: "It is, though, crucial to claim that - until the opposite is proven - that the spectrum is perceived as indivisible in each case: even speakers of languages where it is quite wide nonetheless perceive it as an indivisible whole" 
(p. 843). It is not clear to us why Khanina has not investigated how this subjective (psychological) criterion fares with ready-to-hand languages, such as Spanish.

\section{Khanina's misconstrual of the NSM position on WANT}

As mentioned, it is one of the primary findings of Khanina's study that many languages - as many as 30 in her sample of 73 - lack an exponent of WANT that has no other meanings or functions. We have no wish to refute this claim. What we dispute is her argumentation that this fact invalidates the status of WANT as a universal semantic prime (pp. 844-845, 848).

In her conclusion, Khanina (2008:848) says that waNT cannot be a semantic prime in the NSM sense, because, she says: "[t]here are too many languages all over the world that fail to express it through a distinct word, morpheme, or fixed phrase, a necessary condition for a semantic prime (Goddard 1994: 13)". However, it has never been held by NSM theorists that a given word must be monosemous in order to qualify as an exponent of a semantic prime. The quotation just alluded to, from Goddard (1994: 13), is actually followed immediately by the words: "This does not entail that there should be a single distinct form for each primitive". The burden of the word 'distinct' (which, incidentally, was not italicised in the original) was that a semantically primitive meaning will always be expounded by means of specifically lexical material, by a "segmental sign", and not (for example) by reduplication, or ablaut, or solely through a grammatical construction. This is what NSM researchers mean by the Strong Lexicalisation Hypothesis.

In her conclusion (p. 848), Khanina again quotes one of us as saying that one could disprove a semantic prime by showing that in some language "there is apparently no term whatever which can be used to convey unambiguously the same idea as expressed" (Goddard 1998: 152). Taken out of context, Goddard's wording is perhaps open to being misunderstood, so may we repeat: exponents of semantic primes need not be monosemous, and indeed, they are often not (a point that has been made repeatedly in the NSM literature; e.g. Wierzbicka (1992:13, 1996:25), Goddard (2002b:24-30)). The existence of a term that can be used "unambiguously" to convey the intended meaning of a semantic prime does not necessarily mean "unambiguously in every context". To clarify, consider the situation of Spanish, where as we have seen there is a clear exponent of wANT, i.e. querer ${ }_{1}$. Even in Spanish, there can be contexts in which it is not clear whether a given instance of querer is intended to express the meaning querer ${ }_{1}$ or querer $_{2}$. Such sentences are genuinely ambiguous, i.e. they are open to two semantically different interpretations, or, to put it another way, they can be matched with two different reductive paraphrase explications, one with querer ${ }_{1}$ and the other with a much more com- 
plex explication corresponding to the one given in [A] above. Equally however, there are grammatical contexts in Spanish in which only the meaning querer ${ }_{1}$ is allowable, e.g. in a sentence with an indefinite propositional complement, like Quiero hacer algo 'I want to do something.'

\section{5. "Mass comparisons" vs. targeted in-depth studies}

By their nature, large-scale comparative studies like Khanina's (2008) have to manage problems with data. Even solid descriptive grammars do not necessarily devote much attention to fine points of semantic detail, and, if the truth be told, descriptive linguists are often not very well trained in semantics, compared with their training in fields such as phonetics, phonology, and morphology.

At the beginning of her paper, Khanina is appropriately cautious in her phrasing. When she commented on the possible structural "conditioning" of different meanings expressed by desiderative items, she observed that some grammars report on such structural correlates, while others do not. Can we conclude that if the grammar doesn't report it, it's not there? Of course not, as Khanina rightly notes. Absence of evidence is not evidence of absence. As she proceeds through the study, however, these qualifications and reservations seem to slip away, so that by the end the overall results seem firm and indisputable.

We can illustrate this with reference to how Khanina discusses the distribution of languages with "narrow" vs. "broad/wide" desideratives (p. 846). The former ("languages with desideratives able to denote only wanting in all grammatical contexts") are found all across Eurasia, with the exception of South Asia, and in North America. The languages are so diverse that it seems unreasonable to look for any common structural features, so "it may well depend on some parameters of the culture of the given speech community". In any case, the roughly similar number of languages in each category would suggest that the "narrow/wide" parameter has an equal chance of assuming either value in any language. All this is well and good. We know from other studies that in some parts of the world certain patterns of polysemy are found across linguistic areas, e.g. 'say/do' polysemy in the non-PamaNyungan languages of north-western Australia (Knight 2008:210). We also know that geographically contiguous languages may contrast in this respect, as with Spanish and Basque. What we would like to draw attention to here though is the tone of Khanina's discussion, as she weighs the two possible explanations (linguistic vs. cultural) for the data at hand. Surely she has lost sight of another, equally plausible hypothesis: that some of the putative differences are due to the nature/quality of the linguistic descriptions. To put it another way, at this point in her study Khanina has taken to assuming that all the data is reliable and complete on the point at issue. 
In our view, mass comparisons certainly have their uses, but there is no substitute for detailed language-specific studies. Over the years, NSM researchers have followed up various reports in the literature that imply or state that exponents of semantic primes are "missing" in certain languages; for example, Whorf's (1956) claim that Hopi lacks words for when/Time, Bohnemeyer's (1998) claim that Yucatec Maya does not have (or need) words for BEFORE and AFTER, van Driem's (2004) claim that Nepali lacks an exponent of FEeL, Everett's (2005) claim that Pirahã lacks an exponent for ALL. As far as we can tell on the basis of available evidence (Goddard 2001, 2008: 8-12), those claims have all turned out to be unfounded.

We suspect that careful scrutiny would turn up good language-internal evidence for polysemy in the 30 languages that Khanina lists as having "broad" desideratives. This is a challenge, an invitation, for targeted lexical semantic research. It would be foolhardy to presume the results of such research here, but for a couple of these languages at least, where information is available to us, the indications are positive. Hmong is one of the languages which is supposed to have a single broad desiderative word xav (alternatives: xaav/săy) that can correspond to either 'want' or 'think', with no evidence of polysemy. Khanina notes in passing (p. 832) that the different meanings are associated with different complement structures. In her study of complementation in White Hmong, Jarkey (2006:131-134) provides more detail. Xav as 'want' occurs in a serial-like construction (in same-subject contexts) or with a Potential complementizer kom (in different-subject contexts), as in (3) and (4), respectively.
(3) nws xav yuav koj
3sG want marry $2 \mathrm{sG}$
'He wants to marry you.'
(4) nws xav <kom kuv yuav koj> COMP
3 SG wants to 1 SG marry $2 \mathrm{SG}$
'He wants me to marry you.'

Xav as 'think', however, occurs with a Fact complementizer tias 'that', as in (5); and it can also take a "topic of thought" NP introduced by txog 'about'.

(5) nws xav <tias kuv yuav yuav koj> ${ }_{\text {COMP }}$

3sG thinks that 1SG will marry 2sG

'He thinks that I will marry you.'

To our way of thinking, these differences are language-internal evidence for the polysemy of Hmong xav. Furthermore, the details correspond closely to NSM expectations about the syntactic properties of semantic prime WANT, as opposed to those of semantic prime THINK (Goddard and Wierzbicka 2002:59-63; Goddard 2007). 
Our second example concerns the Australian language Martuthunira (Dench 1995). It is also listed as a language with a broad desiderative word - wiru, which according to Khanina's appendices can correspond to English 'want', 'feel' and 'like/ love. We will only consider the status of the 'feel' translational equivalent here, and in particular the question of whether there is any evidence that it is a genuinely distinct meaning from 'want'. Dench himself does not comment explicitly on this matter, but having examined his grammar, we see some rather suggestive evidence of polysemy. Wiru 'wanting' is described as a two-place nominal predicate (Dench 1995: 157), which also commonly combines with a verbalizing affix -npa (glossed as INCHoative). Both wiru and wirunpa can take a noun-phrase argument in the accusative case, as shown in (6) with wirunpa. From the various examples in Dench's description, it is clear that both nominal wiru and its verbal counterpart wirunpa commonly take clausal complements, as shown in (7) and (8) (see also Khanina's example (7a)). In the different-subjects variant of the clausal complement construction, the actor NP of the complement verb commonly appears outside the complement clause, with the accusative case, in what looks like a classic "raising" construction, as in (8).

(6) Ngayu kamungu-npa-nyila, murla-a wiru-npa-nyila.

1SG.NOM hungry-INCH-PRREL meat-ACC wanting-INCH-PRREL

'I'm getting hungry, wanting meat.' (p. 247)

(7) Ngayu mir.ta wiru kuliya-l.yarra karri-layi nhuwana-a.

1 sG not want hear-CTEMP stand-FUT 2PL-ACC

'I don't want to be hearing you two.' (p. 98)

(8) Ngayu wiru kartungupukarra-a ngurnaa

1sG.NOM wanting 2sG.ACC firewood-ACC that.ACC

piyuwa-ma-lwaa kayulu-marta.

finish-CAUS-PURPS $=0$ water-PROP

'I want you to put out that (smouldering) firewood with water.' (p. 251)

As far as we can see from the examples in Dench (1995), none of the above properties (clausal complement, accusative object, derived verb with -npa) is possible in contexts in which wiru is glossed as 'feelings'. In contexts like these, wiru occurs apposed to the subject NP and modified by an inchoative verb, typically based on panyu 'good'. An example follows (see also Khanina's example (7b)):

(9) Wiru-rru ngayu panyu-npa-nguru.

feelings-NOW 1sG.NOM good-INCH-PRES

'I'll be feeling good.' (p. 276) 
On the face of it, the grammatical contexts in which the two meanings occur are strikingly different. Yet in Khanina's study, Martuthunira is presented as having a desiderative that is undifferentiated between 'want' and 'feel'.

\section{Wider implications: 'Wanting' as a key concept in linguistic typology and cognitive science}

If WANT were not a secure basis for cross-linguistic semantic comparison, the conceptual foundations of important categories in grammatical typology would be undermined. This follows from the fact that cross-linguistic categories in morphology and syntax must be grounded in semantic (conceptual) prototypes (Croft 1990: 12; Wierzbicka 1998; Haspelmath 2007), and that the concept of 'wanting' (or a technical variant such as 'intention', 'motivation', 'purpose', etc.) is a crucial element in many such prototypes. For example, 'wanting' is a crucial element in the conceptual prototypes of the "imperative" ('I want you to do something') and the "interrogative" ('I want to know something, I want you to say something'). The cross-linguistic validity of the notions of "volition" and "control" would also be called into question if 'wanting' were not a viable "comparative concept" (to use an expression of Haspelmath's (forthcoming)).

In speech act theory, the key notion of "illocutionary intention" (Searle 1969) would need to be abandoned, as would a host of other wanting-related concepts in cognitive psychology and the philosophy of mind. Here we mention examples from cognitive anthropology and from cognitive psychology. In a classic article, the anthropologist Roy D'Andrade (1987) explored what he called the "western folk model of the mind" and compared it with a non-western one, as represented by the Ifaluk language of Micronesia. D'Andrade came to the conclusion that there were deep similarities between the two. In particular, "in both models, there seems to be a similar division of internal states into thoughts, feelings, and desires" (p. 4). NSM research converges with D'Andrade when it identifies, in both "western" and "non-western", languages and cultures, distinct categories, similar to those posited by D’Andrade: namely, semantic primes THINK, FEEL and WANT (Goddard 2007). All three are often treated as focal points for discussions of human psychology and cognition, usually under the guise of more technical labels such as cognition, emotion and intention. The universal availability of identifiable lexical exponents for THINK, FEEL and WANT contrasts strikingly with the non-availability of exponents for other comparable concepts which have also sometimes been claimed to be human universals, for example, 'believe' (Gladkova 2007) and 'remember' (Amberber ed. 2007). 
In their important paper "Understanding and sharing intentions: The origins of cultural cognition", the evolutionary psychologist Michael Tomasello and colleagues (2005) write:

We propose that the crucial difference between human cognition and that of other species is the ability to participate with others in collaborative activities with shared goals and intentions: shared intentionality. Participation in such activities requires not only especially powerful forms of intention reading and cultural learning, but also a unique motivation to share psychological states with others and unique forms of cognitive representation for doing so. (emphasis added)

In keeping with the conventions of their discipline, the authors present their hypotheses with the help of technical or semi-technical expressions (such as those emphasized in the quotation, and of course, "social cognition"), but it is not difficult to see that terms like "shared goals", "shared intentionality", and "collaborative activities" are meant to refer, roughly speaking, to 'people wanting the same', 'people wanting to do the same thing', 'people wanting the same things to happen', and also, to 'people wanting to do some things with other people'.

Related to Tomasello's work, there has been a recent surge of interest in "human sociality" (Enfield and Levinson eds. 2006), and, in particular, in how notions of "reciprocity" and "reciprocality" are encoded across the languages of the world. The conceptual core of these notions, we would argue, necessarily involves the concepts of wanting and thinking, as well as 'doing' and 'the same'. For example, a recurrent component in reciprocal constructions in many languages is: 'these two people want to do the same thing' or 'all these people want to do the same thing' (Wierzbicka 2009).

By casting doubt on the universality of WANT, Khanina is casting doubt on the conceptual basis of all these proposals. In effect, she is claiming that thoughts like 'I want to do the same' are sayable (and thinkable) in some natural languages, for example, English and Russian, but not sayable (or thinkable) in others, such as Hmong or Martuthunira. In our view, however, nothing in her paper shows that this is indeed the case.

Based on the available evidence, 'wanting' is a semantic and conceptual universal.

\section{Abbreviations}

1sG first person singular

2SG second person singular

3SG third person singular

ACC accusative
INF infinitive

NOM nominative

Now 'now' discourse clitic

PL plural 


$\begin{array}{llll}\text { CAUS } & \text { causative/factitive } & \text { PRES } & \text { present } \\ \text { CTEMP contemporaneous } & \text { PROP } & \text { proprietive } \\ \text { FUT future } & \text { PrREL } & \text { present relative } \\ \text { INCH inchoative } & \text { PURPS=O } & \text { purposive subject is matrix object }\end{array}$

\section{Notes}

1. Full versions of the natural semantic metalanguage now exist for a number of non-European languages, including Chinese, Korean, Malay, Mbula, Lao, Amharic, Japanese, and East Cree, and targetted studies have been undertaken in Masakai (East Timor), Bunuba (Kimberleys, Australia), Koromu (PNG), and Berber. See Ye 2007a, 2007b; Yoon 2006; Goddard and Wierzbicka eds. 2002; Goddard ed. 2008, among others. A large bibliography is available at the NSM Homepage www.une.edu.au/bcss/nsm.

2. Khanina also spends some time refuting Harkins' (1995) treatment of the Indonesian word suka 'like, want'. Briefly, Harkins argued that it was prime facie evidence of polysemy that some uses of suka are replaceable by mau 'want', while other uses are not. We agree that this argument is not fully convincing, while pointing out that it was not Harkins' only argument. She also observed that the derived verb menukai corresponds to her posited suka $a_{1}$ 'like', but not to $s u k a_{2}$ 'want', and that the prepositions (ke)pada and akan can readily be used with $s u k a_{1}$, but are less acceptable with $s u k a_{2}$. It should also be noted that for Harkins the primary Indonesian exponent of WANT would be mau (not suka ${ }_{2}$ ). Goddard (2002a: 101) nominates mahu and nak as allolexical variants of WANT in neighbouring Malay.

3. Spanish NSM allows for different syntactic patterns for coreferential and non-coreferential subjects of the verb querer WANT, the former occurring with an infinitive verb in the complement clause, and the latter with subjunctive and the complementizer que (Travis 2003).

\section{References}

Amberber, Mengistu (ed.). 2007. The language of memory in a crosslinguistic perspective. Amsterdam: John Benjamins.

Bohnemeyer, Jürgen. 1998. Temporal reference from a radical pragmatics point of view. Why Yucatec Maya does not need to express 'after' and 'before'. Cognitive Linguistics 9(3): 239-282.

Croft, William. 1990. Typology and universals. (Cambridge Textbooks in Linguistics). Cambridge: Cambridge University Press.

D'Andrade, Roy. 1987. The folk model of the mind. Cultural models in language and thought, Dorothy Holland \& Naomi Quinn (eds.), 194-202. Cambridge: Cambridge University Press.

Dench, Alan Charles. 1995. Martuthunira: A language of the Pilbara region of Western Australia. (Pacific Linguistics, Series C-125). Canberra: Pacific Linguistics.

Enfield, N. J. \& Stephen C. Levinson (eds.). 2006. Roots of human sociality: Culture, cognition and interaction. New York: Berg Publishers.

Everett, Daniel L. 2005. Cultural constraints on grammar and cognition in Pirahã. Current Anthropology 46(4): 621-646. 
Gil, David. 2004. Riau Indonesian sama: Explorations in multifunctionality. Coordinating constructions, Martin Haspelmath (ed.), 371-424. Amsterdam: John Benjamins.

Gladkova, Anna. 2007. Universal and language-specific aspects of "propositional attitudes": Russian vs English. Mental states: Volume 2: Language and cognitive structure, Andrea C. Schalley \& Drew Khlentzos (eds.), 61-83. Amsterdam: John Benjamins.

Goddard, Cliff. 1991. Testing the translatability of semantic primitives into an Australian Aboriginal Language. Anthropological Linguistics 33(1): 31-56.

Goddard, Cliff. 1994. Semantic theory and semantic universals. Semantic and lexical universals - Theory and empirical findings, Cliff Goddard \& Anna Wierzbicka (eds.), 7-30. Amsterdam: John Benjamins.

Goddard, Cliff. 1998. Semantic analysis: A practical introduction. Oxford: Oxford University Press.

Goddard, Cliff. 2000. Polysemy: A problem of definition. Polysemy: Theoretical and computational approaches, Yael Ravin \& Claudia Leacock (eds.), 129-151. Oxford: Oxford University Press.

Goddard, Cliff. 2001. Lexico-semantic universals: A critical overview. Linguistic Typology 5(1): $1-66$.

Goddard, Cliff. 2002a. Semantic primes and universal grammar in Malay (Bahasa Melayu). Meaning and universal grammar - Theory and empirical findings, Volume I, Cliff Goddard \& Anna Wierzbicka (eds.), 87-172. Amsterdam: John Benjamins.

Goddard, Cliff. 2002b. The search for the shared semantic core of all languages. Meaning and universal grammar - Theory and empirical findings, Volume I, Cliff Goddard \& Anna Wierzbicka (eds.), 5-40. Amsterdam: John Benjamins.

Goddard, Cliff. 2007. A culture-neutral metalanguage for mental state concepts. Mental states: Volume 2: Language and cognitive structure, Andrea C. Schalley \& Drew Khlentzos (eds.), 11-35. Amsterdam: John Benjamins.

Goddard, Cliff. 2008. Natural Semantic Metalanguage: The state of the art. Cross-linguistic semantics, Cliff Goddard (ed.), 1-34. Amsterdam: John Benjamins.

Goddard, Cliff (ed.). 2008. Cross-linguistic semantics. Amsterdam: John Benjamins

Goddard, Cliff \& Anna Wierzbicka. 2002. Semantic primes and universal grammar. Meaning and universal grammar - Theory and empirical findings, Vol. I, Cliff Goddard \& Anna Wierzbicka (eds.), 41-85. Amsterdam: John Benjamins.

Goddard, Cliff \& Anna Wierzbicka (eds.). 1994. Semantic and lexical universals - Theory and empirical findings. Amsterdam: John Benjamins.

Goddard, Cliff \& Anna Wierzbicka (eds.). 2002. Meaning and universal grammar - Theory and empirical findings. Vols. I and II. Amsterdam: John Benjamins.

Harkins, Jean. 1995. Desire in language and thought: A study in crosscultural semantics. PhD thesis. The Australian National University.

Haspelmath, Martin. 2007. Pre-established categories don't exist - consequences for language description and typology. Linguistic Typology 11: 119-132.

Haspelmath, Martin. Forthcoming. Descriptive categories and comparative concepts in crosslinguistic studies. Ms.. MPI for Evolutionary Antrhopology.

Jarkey, Nerida. 2006. Complement clause types and complementation strategy in White Hmong. Complementation: A cross-linguistic typology, R. M. W. Dixon \& Alexandra Aikhenvald (eds.), 115-136. Oxford: Oxford University Press.

Khanina, Oleshya. 2008. How universal is 'wanting'? Studies in Language 32(4): 818-865. 
Knight, Emily. 2008. Hyperpolysemy in Bunuba, a polysynthetic language of the Kimberley, Western Australia. Cross-linguistic semantics, Cliff Goddard (ed.), 205-223. Amsterdam: John Benjamins.

Peeters, Bert (ed.). 2006. Semantic primes and universal grammar: Empirical findings from the Romance languages. Amsterdam: John Benjamins.

Searle, John. 1969. Speech acts: An essay in the philosophy of language. Cambridge: Cambridge University Press.

Tomasello, Michael, Malinda Carpenter, Josep Call, Tanya Behne \& Henrike Moll. 2005. Understanding and sharing intentions: The origins of cultural cognition. Behavioural and Brain Sciences 28: 675-735.

Travis, Catherine A. 2002. La Metalengua Semántica Natural: The Natural Semantic Metalanguage of Spanish. Meaning and universal grammar - Theory and empirical findings, Vol. I, Cliff Goddard \& Anna Wierzbicka (eds.), 173-242. Amsterdam: John Benjamins.

Travis, Catherine A. 2003. The semantics of the Spanish subjunctive: Its use in the Natural Semantic Metalanguage. Cognitive Linguistics 14(1): 47-69.

van Driem, George. 2004. Review: Cliff Goddard and Anna Wierzbicka (eds.) Meaning and universal grammar - Theory and empirical findings. Language 80(1): 163-165.

Whorf, Benjamin Lee. 1956. Language, thought, and reality: Selected writings of Benjamin Lee Whorf. Edited and with an introduction by John B. Carrol. Cambridge, MA: MIT Press.

Wierzbicka, Anna. 1972. Semantic primitives. Frankfurt: Athenäum.

Wierzbicka, Anna. 1990. The meaning of colour terms: Semantics, culture and cognition. Cognitive Linguistics 1(1): 99-150.

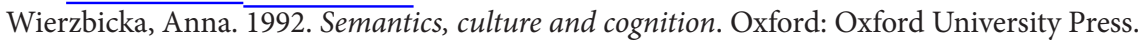

Wierzbicka, Anna. 1996. Semantics: Primes and universals. Oxford: Oxford University Press.

Wierzbicka, Anna. 1998. Anchoring linguistic typology in universal concepts. Linguistic Typology 2(2): 141-194.

Wierzbicka, Anna. 2005. There are no "color" universals, but there are universals of visual semantics. Anthropological Linguistics 47(2): 217-244.

Wierzbicka, Anna. 2008. Why there are no 'colour universals' in language and thought. Journal of the Royal Anthropological Institute (N.S.) 14: 407-425.

Wierzbicka, Anna. 2009. "Reciprocity". An NSM approach to linguistic typology and social universals. Studies in Language 33(1): 103-174.

Ye, Zhengdao. 2007a. Taste as a gateway to Chinese cognition. Mental states: Volume 2: Language and cognitive structure, Andrea C. Schalley \& Drew Khlentzos (eds.), 109-132. Amsterdam: John Benjamins.

Ye, Zhengdao. 2007b. Memorization, learning, and cultural cognition: The notion of bei ('auditory memorizing') in the written Chinese tradition. The language of memory: A crosslinguistic perspective. Mengistu Amberber (ed.), 139-180. Amsterdam: John Benjamins.

Yoon, Kyung-Joo. 2006. Constructing a Korean National Semantic Metalanguage. Seoul: Hankook Publishing Co. 


\section{Authors' addresses}

Prof. Cliff Goddard

School of Behavioral, Cognitive and Social Sciences

Language and Cognition Research Centre University of New England

Armidale NSW 2351 Australia

Fax: +61 267733735

cgoddard@une.edu.au

\section{Anna Wierzbicka}

School of Language Studies

The Australian National University

Canberra ACT 0200 Australia

Anna.Wierzbicka@anu.edu.au 